\title{
Ecological Innovations of Materials in Art Objects to Create a Comfortable Human Environment
}

\author{
Oksana Pylypchuk ${ }^{1, *}$ Olga Krivenko ${ }^{2}$ Andrii Polubok ${ }^{3}$ Andrii Zapryvoda $^{4}$ and \\ Vitalii Zapryvoda ${ }^{5}$
}

\author{
${ }^{1}$ Department of Department of Design, Kyiv National University of Construction and Architecture, 31 Povitroflotsky \\ Avenue, Kyiv, 03037, Ukraine \\ ${ }^{2}$ Department of Architectural Constructions, Kyiv National University of Construction and Architecture, 31 \\ Povitroflotsky Avenue, Kyiv, 03037, Ukraine \\ ${ }^{3}$ Department of Department of Design, Kyiv National University of Construction and Architecture, 31 Povitroflotsky \\ Avenue, Kyiv, 03037, Ukraine \\ ${ }^{4}$ Department of Architectural Constructions Kyiv National University of Construction and Architecture, 31 \\ Povitroflotsky Avenue, Kyiv, Ukraine, 03037 \\ ${ }^{5}$ Department of Architectural Constructions Kyiv National University of Construction and Architecture, 31 \\ Povitroflotsky Avenue, Kyiv, Ukraine, 03037 \\ *Corresponding author. Email: pylypchuk.od@knuba.edu.ua
}

\begin{abstract}
The study developed and proposed an innovative approach based on the use of ecological materials in art objects to create a healthy and comfortable environment. As a result of the analysis of the research, the main structural characteristics of the materials were revealed. Methods for assessing the aesthetic and functional qualities of materials in the modern sphere of their rational use are analyzed. The functional possibilities of using new modern materials in fine art objects are shown. The systematization of materials used in classical forms of art and in modern trends of art has been carried out. An informational-structural model of the choice of artistic material in the creation of objects of fine art, taking into account their properties and characteristics, is proposed. Implementation of research results is shown on the example of author's works. It is proposed to use ecological innovations of materials in art objects when designing an ecological human environment.
\end{abstract}

Keywords: Design, Ecological innovations of materials, Art objects, Comfortable human environment.

\section{INTRODUCTION}

The restrictive measures caused by the COVID-19 pandemic have shown an urgent need to improve the comfort of the human environment. Due to the quarantine, a person is forced to stay in an enclosed space for a long time. At the same time, it should not be devoid of harmony between itself and the environment [1]. The tasks of increasing the comfort, functionality, ergonomics, environmental friendliness and aesthetics of the design of the internal environment are becoming relevant [2-3]. One of the ways to improve the psychological state of a person can be the introduction of various types of fine art into the interior. It is known that art can be a source of admiration and inspiration, evoke emotions of a different nature [4-5]. The feeling of comfort and coziness received from the perception of art improves mood, creates spiritual harmony [6-7]. This is confirmed by the modern international standards for rating certification of buildings "Building Standard WELL", aimed at improving health and improving the quality of life of people with the help of design means, and, accordingly, creating a healthy, ecological and comfortable environment for a person in interiors. In the WELL standards in the sections "Movement" and "Mind" it is indicated that the integration of works of art into various types of interiors increases the rating of a building, and is one of the conditions for reducing stress levels and improving the general health of people in interiors [8].

We must not forget that any artistic object is created with the help of certain materials. For a designer and an artist, it is also a creative material that is used to 
embody a creative idea $[9,10]$. In addition to the functional specifics, the material is capable of evoking certain associations, an emotional range of a different nature (for example, glossy and shiny material, when perceived, is often associated with positive emotions, and matte and dull often evokes negative emotions).

Based on the foregoing, it is relevant to develop a modern innovative approach to the use of certain artistic materials in various types of fine art, in the design of an ecological interior in order to create the desired aesthetic effect and a comfortable human environment, as well as to achieve a certain psychological and emotional state of the recipient.

\section{THE MAIN PART OF THE RESEARCH}

\subsection{Architectonics of Material in Art Objects}

Each material has its own visual characteristics, when due to the texture, texture, color in the given environmental conditions, they produce a different impression on perception. Associated sensations are associated with the material - heat and cold, heaviness and lightness, strength, hardness and softness [11-13]. Also, the material of the surface of the object of art can create a certain optical effect, depending on the coating, quality and processing methods of the material of manufacture [14-15]. Modern science, thanks to the development of new technologies, has created a large number of materials for creativity that are new in their structure, thereby enriching the arsenal of the artistdesigner. Due to the variety of properties of materials, a modern artist is free in their choice to realize its creative idea.

\subsection{Analysis of New Possibilities of Fine Art in Interior Design Using Innovative Materials}

All materials used in the creation of various works of art differ in their purpose, composition, properties and manufacturability. In general, the term "material" refers to the original item used to make a product [16]. Intensive scientific and technological development opens up wide opportunities for innovation in various spheres of human activity, including in the visual arts, ensuring the development of new materials and technologies for the work of artists and designers.

The expansion of the qualities of the functional capabilities of new modern materials develops and complements the artistic and graphic and decorative properties of objects of fine art [17]. Innovative materials are able to enhance and enrich the artistic possibilities of the fine arts, evoking emotions of a different nature in a person. Thus, the use of new materials in art objects, in addition to the creative principle in solving form, color, tectonics, composition, carries new qualities: environmental safety, innovation, efficiency, versatility. For example, the use of fluorescent paints (self-luminous paints applied to an object of art are able to give off the accumulated light energy, increasing energy efficiency and visibility in the room [11]). Thermochromic paints are capable of changing their color, producing new unexpected effects on perception. Polymers and various types of plastics (carbon composite material consisting of graphite fiber embedded in an epoxy matrix) is a modern highstrength and at the same time lightweight material in its structure, capable of imitating various types and breeds of materials [18]. Acrylic is a type of plastic used in works of art as an alternative to natural material, provides resistance to the microclimate of the interior and time with high environmental friendliness [9]. An innovative way of printing on a 3D printer, the use of nanotechnology to create shapes that are complex in their structure, influenced the emergence of a new direction in the visual arts - nano-art [19], (Fig. 1, a-c).

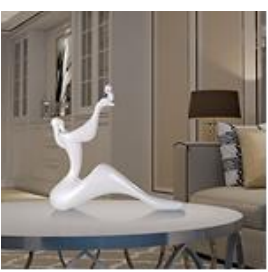

(a)

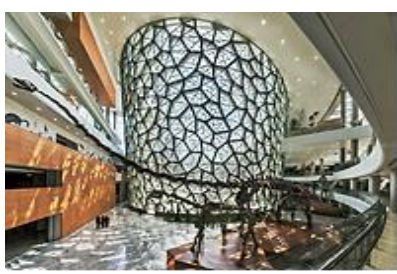

(b)

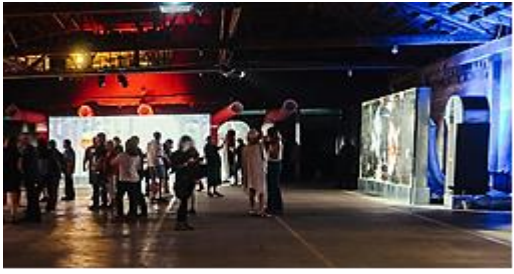

(c)

Figure 1 (a-c). The use of modern innovative materials in art objects to create interior spaces for various purposes.

Key to Figure 1 (a-c):

(a) - sculpture made of synthetic materials in a living space [24];

(b) - decorative architectural forms made using nanotechnology in the space of a modern museum (Shanghai Natural History Museum) [25];

(c) - paintings made with thermochromic paints in the exhibition hall [26].

Thus, innovative materials, when used in fine art objects, provide: 1) versatility - the ability to use to achieve unlimited creative possibilities; 2) multifunctionality - objects of contemporary art can combine several possibilities at once - to be a source of emotional stress, create various associations, solve utilitarian tasks (lighting, heating); 3) manufacturability - due to resistance to external influences, ensure wear resistance, durability; 
4) environmental friendliness - no toxic or irritating substances, minimum level of radioactive radiation, suitable for reuse, recyclable or can be completely disposed of.

\section{STRUCTURAL ANALYSIS}

The implementation of the creative idea of artistsdesigners through the use of objects of fine art in interior design depends, among other things, on the surface properties of the material used and the nature of its processing. In the course of the analysis, interdisciplinary studies in various fields were studied, such as psychology of perception, art theory, restoration, chemistry and others [18, 20-23]. Methods for assessing the aesthetic and functional qualities of materials in the modern sphere of their rational use have been analyzed $[10,12,18,19]$. The study took into account the results of the author's practice in the field of design and the creative experience of creating various objects of fine art [24].

On the basis of theoretical analysis and practical experience, an information-structural model for the choice of artistic material for objects of fine art was developed, taking into account their properties and characteristics. The information-structural model is based on the analysis of the properties of various artistic materials for variant modeling when deciding on the possible emotional component in the perception of a fine art object in interior design.

Based on the fact that various objects of fine art are used in modern design, both traditional classical materials and innovative materials are included in the information-structural model. As a result, the following artistic performance materials were identified:

1. In painting: oil paints; acrylic, tempera, watercolor, gouache; enamel, PVA (polyvinyl acetate) water emulsion, water dispersion, silicate, mineral; encaustics, fluorescent paints and neon materials.

2. In graphics: various types of colored pencils, crayons, felt-tip pens, ink.

3. In sculpture: metal, cement, gypsum, natural stone, natural wood, ceramics (glaze, enamel, terracotta, faience, chamotte, etc.), glass, synthetic materials (various types of plastic and resins).

4. In surface decoration: colored foil (gilding, silvering, patination, etc.), paper (decoupage, papiermâché), for inlay technique, mosaic, collage.

5. Modern technologies used in "Contemporary art": thermochromic paints; nano-solution, polymer paste, organic resins.

The main results are presented in the information-

Table 1. Information-structural model of decision-making in the use of fine art materials in the interior space (fragment)

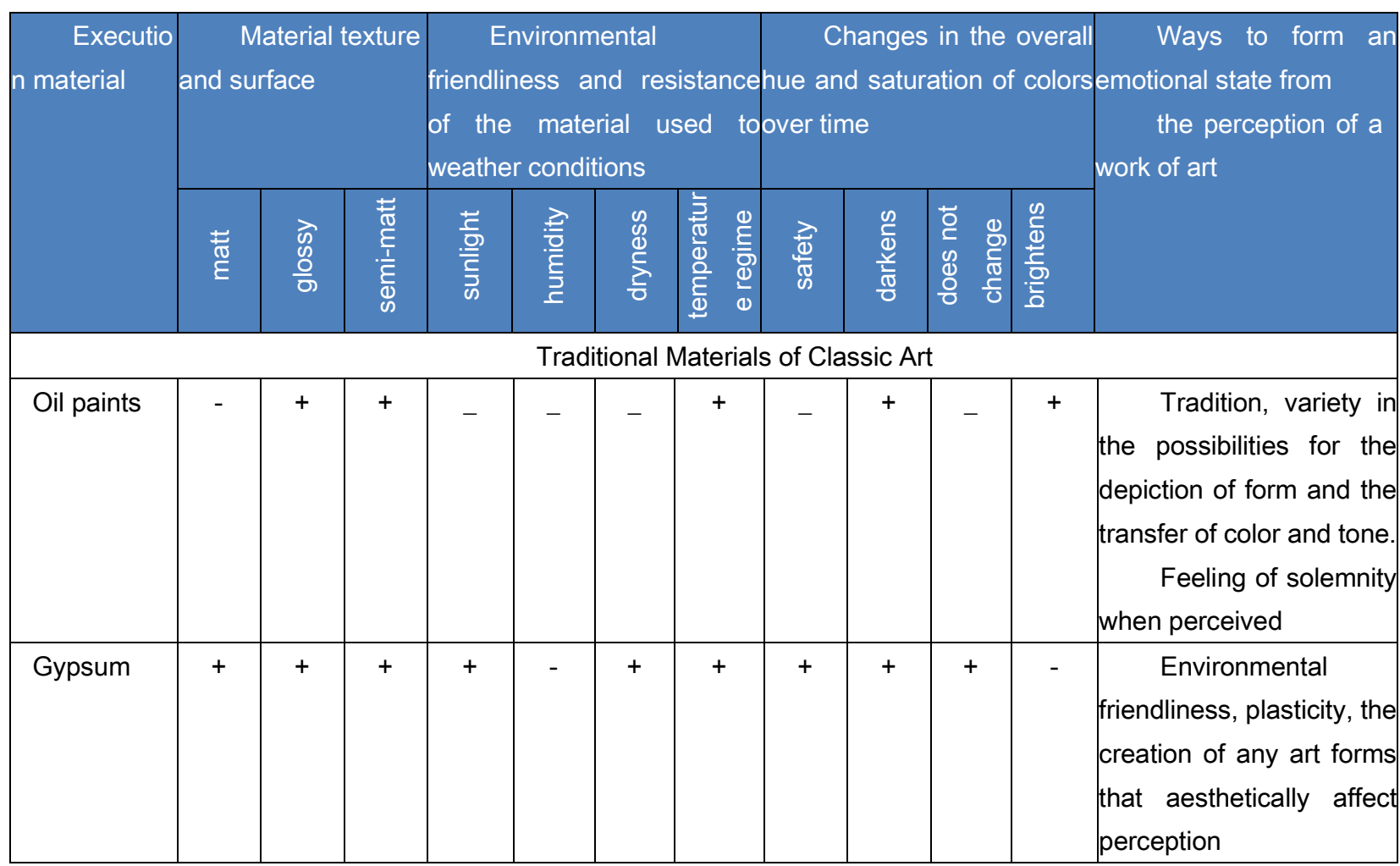

choice of material regarding the creative concept, execution technique, functional tasks, as well as the structural model, a fragment of which see in Table 1. 


\begin{tabular}{|c|c|c|c|c|c|c|c|c|c|c|c|c|}
\hline \multicolumn{13}{|c|}{ Table 1, cont } \\
\hline \multicolumn{13}{|c|}{ Innovative Materials of Contemporary Art } \\
\hline $\begin{array}{l}\text { Organic } \\
\text { resins }\end{array}$ & + & + & + & + & + & + & + & + & - & + & - & $\begin{array}{l}\quad \begin{array}{l}\text { Ability } \\
\text { to simulate } \\
\text { materials of various } \\
\text { structures. }\end{array} \\
\text { creative experimentation } \\
\text { and emotional impact } \\
\end{array}$ \\
\hline $\begin{array}{l}\text { Nano- } \\
\text { solution }\end{array}$ & + & + & + & + & + & + & + & + & - & + & - & \begin{tabular}{l}
\multicolumn{1}{c}{ Modeling new } \\
complex forms that are \\
impossible in traditional \\
materials, unlimited \\
emotional impact
\end{tabular} \\
\hline $\begin{array}{l}\text { Thermochro } \\
\text { mic paints }\end{array}$ & + & + & + & + & + & + & + & + & + & + & + & $\begin{array}{l}\text { Energy saving } \\
\text { opportunities. Creation of } \\
\text { various effects and } \\
\text { illusions that emotionally } \\
\text { affect perception }\end{array}$ \\
\hline $\begin{array}{l}\text { Polymer } \\
\text { paste }\end{array}$ & + & - & + & + & + & + & + & - & - & + & + & $\begin{array}{l}\text { Plasticity, high } \\
\text { strength, a large number } \\
\text { of execution techniques } \\
\text { in creating a variety of } \\
\text { decorative forms for } \\
\text { different emotional impact }\end{array}$ \\
\hline
\end{tabular}

On the basis of the developed and instrumental variant model, artistic compositions were introduced and implemented in interiors for various purposes (Fig. 2, a-e).

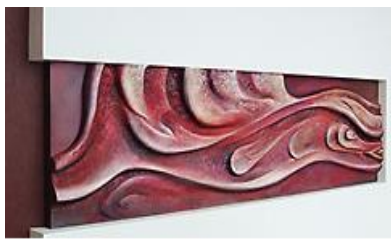

(a)

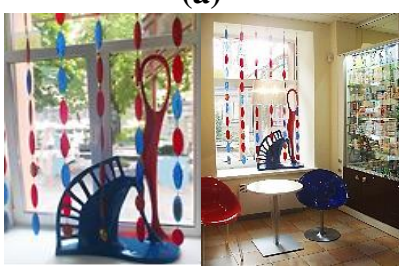

(c)

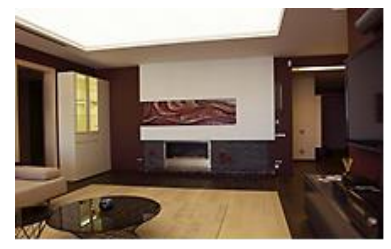

(b)

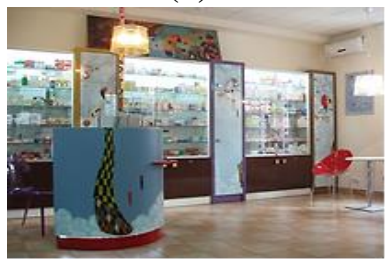

(e)
Figure 2 (a-e). Realization of objects of fine art, which were developed and executed by the authors (artistdesigner - O. Pylypchuk, sculptor - A. Polubok [24]), based on the research presented in the article.

Key to Figure 1 (a-e):

(a) - wall relief made of plaster tinted with an acrylic-based composite material. The semi-matt shine of the coating does not destroy the relief shape, but reveals it, at the same time producing a positive emotional effect in the complex compositional solution of this interior. Environmental friendliness and safety, durability of the materials used, practicality for a residential interior;

(c, d) - a sculptural composition made of epoxy resin with the addition of a colored pigment. The glossy shine of the material and the brightness of the color have a positive effect on the recipient in a complex solution of this interior. The manufacturability of modern material makes the sculpture durable for use in public interiors;

(e) - decorating pharmacy furniture using decoupage technique. The use of environmentally friendly materials does not contradict the hygienic standards of the premises and brings harmony to the overall composition, creating a positive mood among the visitors of the pharmacy;

(b, e) - compositional arrangement of a visual art object in the interior space. In addition to fulfilling the aesthetic utilitarian function of an artistic object, it is subordinated to the general complex spatial solution and the figurative idea of the entire interior.

Thus, the structural characteristics of the material used in the objects of fine art included in the interior space determine their aesthetic and functional qualities. 


\section{DISCUSSION}

Modern interior design associates the use of contemporary art with solving the problem of creating an ecological internal environment, its aesthetics and functionality, where one of the main aggregate elements is the use of objects of fine art [3, 6-8]. New stylistic directions associated with the development of the latest technologies are relevant. A significant number of studies have been devoted to these issues $[12,28]$. But, unfortunately, to date, systemic studies on the problem of creating an ecological interior with the desired aesthetic effect using artistic materials for a comfortable human environment are insufficiently developed. Accordingly, the innovative design approach proposed in the article is promising.

\section{CONCLUSIONS}

Artistic material in fine art objects is able to indirectly participate in solving various problems of designing internal space and aesthetic perception of the environment around a person. It is also a factor in achieving artistic expressiveness, imagery when solving aesthetic, stylistic, and thematic tasks, setting the appropriate emotional load in accordance with the creative concept in interior design.

The developed and proposed information-structural model can serve as the basis for a conscious choice of artistic material for objects of fine art, taking into account their properties and characteristics to improve the aesthetic, emotional and functional qualities of interior design in accordance with modern needs and human living conditions.

\section{REFERENCES}

[1] O. Pylypchuk, Determination of methods for improving the aesthetic of the environment with the help of visual art, Colloquium-j. 30(82) (2020) 4-6. DOI: https://doi.org/ 10.24412/2520-24802020-3082-4-6

[2] P. Jayathissa, M. Quintana, M. Abdelrahman, C. Miller, Humans - as - a - Sensor for Buildings - Intensive Longitudinal Indoor Comfort Models, Buildings 10(10):174 (2020) 2-22. DOI: https://doi.org/10.3390/buildings 10100174

[3] Q. Zhenfeng, Analysis of the integration of indoor ecological landscape design and interior decoration design, Advances in Engineering Research 173(2018) 364-369. DOI: https://doi.org/10.2991/wartia-18.2018.67

[4] M. Nan, H-W. Chau, J. Zhou, M. Noguchi, Structuring the Environmental Experience Design Research Framework through Selected Aged Care Facility Data Analyses in Victoria, J. Sustainability
9(12) (2017) 173-193. DOI:

https://doi.org/10.3390/su9122172

[5] I.Z. Stojilović, S. Marković, Evaluation of Paintings, Psihologija by the Serbian Psych. Association 4(47) (2014) 415-432. DOI: https://doi.org/10.2298/PSI1404415S

[6] L. Lankston, P. Cusack, C. Fremantle, C. Isles, Visual art in hospitals: case studies and review of the evidence, J. of the Royal Society of Medicine 103(12) (2010) 490-499. DOI: https://doi.org/10.1258/jrsm.2010.100256

[7] Q. Wang, Analysis of Interior Space Design and Visual Artistic Effect, 1st International Conference on Education Art Management and Social Sciences (EAMSS 2018), pp. 362-366. DOI: https://doi.org/10.23977/eamss.2018.075

[8] Building Standard WELL 2021, URL: https://www.wellcertified.com (date retrieved: 27.02.2021).

[9] M.J.P. Van Zuijlen, S.C. Pont, M.W.A. Wijntjes, Painterly depiction of material properties, J. of Vision 20(7) (2020) 1-17. DOI: https://doi.org/10.1167/jov.20.7.7

[10] C. Ishiguro, H. Takagish, Y. Sato, A. W. Seow, A. Takahashi, Y. Abe, T. Hayashi, H. Kakizaki, K. Uno, H. Okada, E. Kato, Effect of dialogical appreciation based on visual thinking strategies on art-viewing strategies, Psych. of Aesth. Creativity and the Arts 15(1) (2021) 51-59. DOI: https://doi.org/10.1037/aca0000258

[11] O. Pilipchuk Y. Kolomiiets, Elaboration of main methods of using coloristics at creating the ecological interior space including artworcs, EUREKA: Art and Hum. 3(2019) 3-8. DOI: https://doi.org/10.21303/2504-5571.2019.00905

[12] M.J.P. Van Zuijlen, S. C. Pont, M. W. A. Wijntjes, Painterly depiction of material properties, J. of Vision 20(7):7 (2020) 1-17. DOI: https://doi.org/10.1167/jov.20.7.7

[13] B. Sayim, P. Cavanagh, The Art of Transparency, vol. 1, I-Perception, 2011, pp. 679-696. DOI: https://doi.org/10.1068/i0459aap

[14] A.C. Chadwick, R.W. Kentridge, The perception of gloss, Vision Research, 109(PB) (2015) 221-235. DOI: https://doi.org/10.1016/j.visres.2014.10.026

[15] C.B. Wiebel, M. Toscani and K.R. Gegenfurtner, Statistical correlates of perceived gloss in natural images, Vision Research 115(2015) 175-187. DOI: https://doi.org/10.1016/j.visres.2015.04.010 
[16] E.H. Adelson, On Seeing Stuff: The Perception of Materials by Humans and Machines, vol. 4299, Proceedings of the SPIE, 2001, 1-12. DOI: https://doi.org/10.1117/12.429489

[17] Materials Coursework Guide, URL: https://www.tate.org.uk/art/student-resource/exam help/materials (date retrieved: 27.02.2021).

[18] M. Jadzinska, P. Parzuchowski, New Materials in Works of Art (Plastics) - The Challenge of Our Times Synergy in the Field of Recognition Damage Assessment and Protection, Conference: International Conference on Cultural Heritage EUROMED November 2014, At: Limassol Cypr Preservation and Conservation in Cultural Heritage, pp. 567-578.

[19] O. Pylypchuk, A. Polubok, O. Krivenko, Influence of environmental aspects of design on the aesthetics of architectural space, Materials of the International Scientific and Practical Conference: Science engineering and technology: global trends problems and solutions, 25-26 September 2020, Czech Technical University, pp. 122-124. DOI: https://doi.org/10.30525/978-9934-588-79-2-2.29

[20] O. Pilipchuk, A. Polubok, Solution of creative design of artistic and decorative form depending on the used materials, ScienceRise 4(57) (2019) 36-39. DOI: https://doi.org/10.15587/23138416.2019.164772

[21] F.D. Cicco, L. Wiersma, M. Wijntjes, S. Pont, Material Properties and Image Cues for Convincing Grapes: The Know-How of the 17thCentury Pictorial Recipe by Willem Beurs, Brill, 8(3-4) (2020) 337-362. DOI: 10.1163/22134913bja10019

[22] R.W. Fleming, K.R. Gegenfurtner, S. Nishida, Visual perception of materials: Thescience of stuff, Vision Research 109(B) (2015) 123-124. DOI: https://doi.org/10.1016/j.visres.2015.01.014

[23] A. Miscena, J. Arato, R. Rosenberg, Absorbing the gaze scattering looks, J. of Eye Movement Research 13(2):8 (2020) 1-11. DOI: https://doi.org/10.16910/jemr.13.2.8

[24] Delicate Mom and Child, URL: https://imall.com/product/Delicate-Mom-ChildLift-Resin-Sculpture-House-Decorative-StatueHome-Office-Desktop-Decor-Modern-AbstractNice-Art-Figurine/Garden-StatuesSculptures/aliexpress.com/32913048354/1443812587/uk (date retrieved: 16.04.2021).

[25] Shanghai Natural History Museum/Perkins, Will, 3(2020) [online]. URL: https://www.archdaily.com/623197/shanghainatural-history-museum-perkins-will (date retrieved: 1.03.21).

[26] Degrees of Perfect Behind the murals that morph, URL: https://mashable.com/2016/07/13/thermochr omic-murals-exhibit/ (date retrieved: 1.03.21).

[27] Oksana Pilipchuk - gallery, URL: http://oksanapilipchuk.com.ua/index.php/en/ (date retrieved: 1.03.21)

[28] Trends of Contemporary Art in Innovative Interior Architecture Design of Cultural Spaces Cities' Identity Through Architecture and Arts, Part of the Advances in Science Technology \& Innovation book series (ASTI) 29(11) (2020) 25-57. DOI: https://doi.org/10.1007/978-3-030-14869-0_3 